\title{
Alanine Aminotransferase Is Associated With Metabolic Syndrome Independently of Insulin Resistance
}

\author{
Ji Eun Yun, PhD; Sang Yeun Kim; Hee-Cheol Kang, MD, PhD; \\ Sun Ju Lee; Heejin Kimm, MD, PhD; Sun Ha Jee, PhD
}

\begin{abstract}
Background: Few studies have examined the effect of insulin resistance on the association between alanine aminotransferase (ALT) and metabolic syndrome. The association between ALT levels and metabolic syndrome were determined, independently of insulin resistance in Korean populations.
\end{abstract}

\begin{abstract}
Methods and Results: The association between ALT and metabolic syndrome were examined in 28,456 subjects who visited 7 Health Promotion Centers at University Hospitals in Korea from 2006 to 2008. HOMA-IR index was used to represent insulin resistance index. ALT levels were found to be positively associated with metabolic syndrome after adjusting for age, alcohol intake, and smoking status. Furthermore, when additional adjustment was made for insulin resistance, this association between ALT and metabolic syndrome, although slightly attenuated, remained strongly significant. Subjects in the highest ALT quartile were found to have a higher risk of having metabolic syndrome than those in the lowest quartile (odds ratio $(O R)=4.45,95 \%$ confidence interval $(\mathrm{Cl})=3.96-4.99$ for men and $\mathrm{OR}=3.51,95 \% \mathrm{Cl}=2.73-4.52$ for women). In addition, the association between ALT level and the risk of metabolic syndrome was significantly higher in the relatively low risk group.
\end{abstract}

Conclusions: ALT levels were found to be significantly associated with metabolic syndrome independently of insulin resistance and with an interaction by age. Further cohort studies are needed to determine the usefulness of ALT levels for predicting the risk of metabolic syndrome. (Circ $J$ 2011; 75: 964-969)

Key Words: Alanine aminotransferase; Insulin resistance; Metabolic syndrome

$\mathbf{M}$ etabolic syndrome is highly prevalent among the general populations, and is associated with the subsequent development of type 2 diabetes and cardiovascular disease. ${ }^{1-5}$ Moreover, metabolic syndrome has been found to be strongly association with mortality due to coronary heart disease, cardiovascular disease, and all causes. ${ }^{6-9}$ Alanine aminotransferase (ALT) has been reported to be an indicator of liver function ${ }^{10-12}$ and to be associated with insulin resistance and metabolic syndrome. ${ }^{13-15}$ In addition, insulin resistance has been associated with fat liver and ALT with liver fat accumulation. ${ }^{16}$ Recently, several studies concluded that ALT elevation is associated with insulin resistance and oxidative stress, which are known to increase the risk of metabolic syndrome. However, although several previous studies have shown the association between ALT and metabolic syndrome, ${ }^{13,17,18}$ a few studies have examined the effect of insulin resistance on the association between ALT and metabolic syndrome. ${ }^{19}$ Therefore, this present study was undertaken to confirm the association between ALT levels and metabolic syndrome and to determine the significance of the association between ALT levels and metabolic syndrome independently of insulin resistance among Korean populations.

\section{Study Subjects}

Data were obtained from 32,208 subjects who visited 7 Health Promotion Centers at University Hospitals in Korea from January 2006 to November 2008. Among the total subjects, 2,222 subjects were excluded if they reported having any liver disease or positive hepatitis B (HBsAg). In addition, the individuals with missing information about gender, smoking status, alcohol intake, exercise, ALT or insulin were excluded. Components of metabolic syndrome, such as, waist circumference, blood pressure, and serum fasting glucose high-density lipoprotein (HDL) cholesterol, and triglyceride (TG) concentrations were measured. Thus, the final cohort

Received May 13, 2010; revised manuscript received November 12, 2010; accepted December 1, 2010; released online February 4, 2011 Time for primary review: 32 days

Institute for Health Promotion, Yonsei University, Seoul (J.E.Y., S.Y.K., S.J.L., H.K., S.H.J.); Department of Epidemiology and Health Promotion, Graduate School of Public Health, Yonsei University, Seoul (J.E.Y., H.K., S.H.J.); Metabolic Syndrome Research Initiatives, Seoul (S.Y.K., S.J.L.); and Department of Family Medicine, Yonsei University College of Medicine, Seoul (H.-C.K.), Korea

Mailing address: Sun Ha Jee, MHS, PhD, Department of Epidemiology and Health Promotion, Graduate School of Public Health, Yonsei University, Seoul, Korea. E-mail: jsunha@yuhs.ac

ISSN-1346-9843 doi:10.1253/circj.CJ-10-0465

All rights are reserved to the Japanese Circulation Society. For permissions, please e-mail: cj@j-circ.or.jp 
was composed of 29,319 subjects (18,290 men and 11,029 women). The Institutional Review Board of Human Research at Yonsei University (Seoul) approved this study, and written informed consent was obtained from all participants.

\section{Data Collection}

Participants were interviewed individually using a structured questionnaire to collect information on smoking history (never smoked, ex-smoker, or current smoker) and alcohol consumption, ie, non-drinker or consumers of any amount of alcohol on a regular basis, and on other demographic characteristics, such as, age, gender, and a history of liver disease. Waist circumference was measured midway between the lower rib and iliac crest, and participants' heights and weights were measured while wearing light clothing. Body mass index (BMI) was calculated by dividing weight $(\mathrm{kg})$ by height squared $\left(\mathrm{m}^{2}\right)$. Systolic and diastolic blood pressures were measured after a $15 \mathrm{~min}$ rest.

\section{Measurement of Biomarkers}

For clinical chemistry assays, serum samples were obtained from peripheral venous blood samples obtained after a $12 \mathrm{~h}$ fast, and then stored at $-70^{\circ} \mathrm{C}$ for $2 \mathrm{~h}$. Biomarkers for metabolic syndrome, namely, fasting blood glucose, total cholesterol (TC), TG, and HDL cholesterol levels, were measured using a Hitachi-7600 analyzer (Hitachi Ltd, Tokyo, Japan). The HOMA-IR index was calculated from fasting serum insulin concentrations, as follows; fasting serum insulin (microunits per milliliter) $\times$ fasting plasma glucose (millimoles per L)/22.5. Subjects with a HOMA-IR of $\geq 1.32$ were allocated to the highest quartile for insulin resistance. The data quality control procedures used complied with the guidelines issued by the Korean Association of Laboratory Quality Control.

\section{Statistical Analysis}

The odds ratios (OR) of serum ALT levels for the risk of metabolic syndrome were assessed by classifying ALT quartiles into men and women. The serum ALT levels quartiles were as follows: $<17.0,17.0-22.9,23.0-32.9$, and $\geq 33.0 \mathrm{IU} / \mathrm{L}$ for men, and $<11.0,11.0-14.9,15.0-19.9$, and $\geq 19.0 \mathrm{IU} / \mathrm{L}$ for women. Multiple logistic regression models were used to assess the independent effect of ALT on the risk of metabolic

\begin{tabular}{|c|c|c|}
\hline & $\begin{array}{c}\text { Men } \\
(n=18,290)\end{array}$ & $\begin{array}{c}\text { Women } \\
(n=11,029)\end{array}$ \\
\hline & Mean \pm SD & Mean \pm SD \\
\hline Age, years & $43.6 \pm 10.0$ & $42.8 \pm 10.7$ \\
\hline $\mathrm{BMI}, \mathrm{kg} / \mathrm{m}^{2}$ & $24.4 \pm 2.8$ & $22.4 \pm 3.0$ \\
\hline Waist circumference, $\mathrm{cm}$ & $84.3 \pm 7.7$ & $74.0 \pm 8.2$ \\
\hline Systolic BP, mmHg & $122.9 \pm 13.4$ & $114.1 \pm 14.7$ \\
\hline Diastolic BP, mmHg & $77.8 \pm 10.5$ & $71.8 \pm 10.2$ \\
\hline Total cholesterol, mg/dl & $190.6 \pm 32.5$ & $183.3 \pm 33.0$ \\
\hline Triglyceride, mg/dl & $156.4 \pm 100.2$ & $100.6 \pm 60.6$ \\
\hline HDL cholesterol, mg/dl & $48.8 \pm 9.6$ & $57.3 \pm 11.6$ \\
\hline Fasting glucose, mg/dl & $93.3 \pm 20.2$ & $87.6 \pm 14.2$ \\
\hline ALT, IU/L & $24.2 \pm 11.4$ & $19.5 \pm 6.7$ \\
\hline Alanine aminotransferase, IU/L & $28.4 \pm 19.4$ & $16.7 \pm 10.1$ \\
\hline HOMA & $1.1 \pm 0.8$ & $1.0 \pm 0.7$ \\
\hline \multicolumn{3}{|l|}{ Smoking status (\%) } \\
\hline Ex-smoker & 31.6 & 2.7 \\
\hline Current smoker & 42.6 & 3.9 \\
\hline Alcohol intake (\%) & 87.6 & 49.8 \\
\hline Metabolic syndrome (\%) & 31.9 & 14.7 \\
\hline
\end{tabular}

$\mathrm{SD}$, standard deviation; BMI, body mass index; BP, blood pressure; $\mathrm{HDL}$, high-density lipoprotein; ALT, alanine aminotransferase.

syndrome on both genders, and to determine the additional effects of age.

Metabolic syndrome was defined as the presence of at least 3 of the 5 characteristics of metabolic syndrome described by the Third Adult Treatment Panel (ATP III) of the Korean National Cholesterol Education Program ${ }^{20}$ and waist circumference cutoffs were modified by Asian criteria. ${ }^{21}$

The following were used for definition of metabolic syndrome:

(1) Abdominal obesity: a waist circumference of $\geq 90 \mathrm{~cm}$ for men and $\geq 80 \mathrm{~cm}$ for women.

(2) High TG: a TG concentration of $\geq 150 \mathrm{mg} / \mathrm{dl}$.

(3) Low HDL cholesterol: HDL cholesterol $<40 \mathrm{mg} / \mathrm{dl}$ for men and $<50 \mathrm{mg} / \mathrm{dl}$ for women.

\begin{tabular}{|c|c|c|c|c|c|c|c|c|}
\hline & \multicolumn{4}{|c|}{ Men } & \multicolumn{4}{|c|}{ Women } \\
\hline & Quartile 1 & Quartile 2 & Quartile 3 & ${\text { Quartile } 4^{\dagger}}^{\dagger}$ & Quartile 1 & Quartile 2 & Quartile 3 & ${\text { Quartile } 4^{\dagger}}^{-}$ \\
\hline N & 3,875 & 4,751 & 5,006 & 4,658 & 2,042 & 3,578 & 2,492 & 2,917 \\
\hline ALT, IU/L & $13.5 \pm 2.1$ & $19.4 \pm 1.7$ & $26.8 \pm 2.8$ & $51.7 \pm 25.5$ & $8.8 \pm 1.3$ & $12.5 \pm 1.1$ & $16.3 \pm 1.1$ & $27.8 \pm 14.0$ \\
\hline Age, years & $43.8 \pm 10.8$ & $44.4 \pm 10.3$ & $44.4 \pm 9.7$ & $41.9 \pm 9.1$ & $37.9 \pm 8.5$ & $40.7 \pm 9.7$ & $44.3 \pm 10.8$ & $47.3 \pm 11.0$ \\
\hline $\mathrm{BMI}, \mathrm{kg} / \mathrm{m}^{2}$ & $22.9 \pm 2.4$ & $23.8 \pm 2.4$ & $24.6 \pm 2.6$ & $25.9 \pm 2.9$ & $21.4 \pm 2.4$ & $21.9 \pm 2.7$ & $22.6 \pm 3.0$ & $23.7 \pm 3.5$ \\
\hline Waist circumference, $\mathrm{cm}$ & $80.4 \pm 7.2$ & $82.9 \pm 6.9$ & $85.1 \pm 7.1$ & $88.3 \pm 7.5$ & $71.0 \pm 6.7$ & $72.5 \pm 7.2$ & $74.4 \pm 8.0$ & $77.6 \pm 9.1$ \\
\hline Systolic BP, mmHg & $120.2 \pm 13.1$ & $121.8 \pm 13.3$ & $123.4 \pm 13.2$ & $125.6 \pm 13.4$ & $110.6 \pm 12.5$ & $112.4 \pm 14.1$ & $114.6 \pm 14.6$ & $118.3 \pm 15.8$ \\
\hline Diastolic BP, mmHg & $75.5 \pm 10.1$ & $77.1 \pm 10.3$ & $78.2 \pm 10.4$ & $79.8 \pm 10.6$ & $69.8 \pm 9.2$ & $70.8 \pm 9.7$ & $72.3 \pm 10.4$ & $73.9 \pm 10.8$ \\
\hline Total cholesterol, mg/dl & $180.5 \pm 29.9$ & $187.2 \pm 30.5$ & $193.2 \pm 32.1$ & $199.7 \pm 34.2$ & $172.1 \pm 28.1$ & $179.4 \pm 30.7$ & $186.8 \pm 32.8$ & $193.0 \pm 35.9$ \\
\hline Triglyceride, mg/dl & $116.5 \pm 63.1$ & $136.0 \pm 77.4$ & $162.4 \pm 98.4$ & $203.7 \pm 124.9$ & $81.4 \pm 41.3$ & $89.6 \pm 42.5$ & $101.2 \pm 56.1$ & $127.1 \pm 81.7$ \\
\hline HDL cholesterol, mg/dl & $51.0 \pm 10.1$ & $49.9 \pm 9.7$ & $48.5 \pm 9.4$ & $46.2 \pm 8.8$ & $58.5 \pm 11.1$ & $57.9 \pm 11.3$ & $57.4 \pm 11.7$ & $55.4 \pm 12.0$ \\
\hline Fasting glucose, mg/dl & $90.9 \pm 18.4$ & $91.8 \pm 17.5$ & $94.0 \pm 21.0$ & $96.2 \pm 22.9$ & $84.9 \pm 8.6$ & $86.0 \pm 11.8$ & $87.3 \pm 12.2$ & $91.8 \pm 19.6$ \\
\hline HOMA & $0.8 \pm 0.5$ & $0.9 \pm 0.6$ & $1.1 \pm 0.7$ & $1.6 \pm 1.0$ & $0.8 \pm 0.5$ & $0.9 \pm 0.5$ & $0.9 \pm 0.6$ & $1.2 \pm 0.8$ \\
\hline
\end{tabular}

Abbreviations see in Table 1.

Data are presented as means \pm SD.

${ }^{*}$ Gender-specific quartile mean of ALT: men $(<17.0,17.0-22.9,23.0-32.9, \geq 33.0 \mathrm{IU} / \mathrm{L})$, women $(<11.0,11.0-14.9,15.0-18.9, \geq 19.0 \mathrm{IU} / \mathrm{L})$.

tP for trend was significant for all variables $(<0.0001)$ by regression analyses. 
Table 3. Age, Alcohol Intake, Smoking Status and Insulin Resistance Adjusted Correlations Between ALT and Metabolic Syndrome Components

\begin{tabular}{|c|c|c|c|c|}
\hline & \multicolumn{2}{|c|}{ Men } & \multicolumn{2}{|c|}{ Women } \\
\hline & Model $1^{\dagger}$ & Model $2^{\ddagger}$ & Model $1^{\dagger}$ & Model $2^{\ddagger}$ \\
\hline Systolic BP & $0.135^{\star *}$ & $0.091^{\star \star}$ & $0.072^{\star *}$ & $0.044^{\star \star}$ \\
\hline Diastolic BP & $0.133^{* *}$ & $0.096^{\star \star}$ & $0.059^{* *}$ & $0.038^{\star *}$ \\
\hline Waist circumference & $0.326^{* *}$ & $0.249^{\star \star}$ & $0.201^{* *}$ & $0.162^{\star \star}$ \\
\hline Triglyceride & $0.272^{\star *}$ & $0.207^{\star *}$ & $0.199^{* *}$ & $0.162^{* *}$ \\
\hline HDL cholesterol & $-0.155^{\star \star}$ & $-0.111^{* *}$ & $-0.074^{\star \star}$ & $-0.046^{\star *}$ \\
\hline Fasting blood glucose & $0.135^{\star *}$ & $0.052^{\star \star}$ & $0.105^{\star *}$ & $0.058^{\star *}$ \\
\hline
\end{tabular}

Abbreviations see in Table 1.

Correlation coefficients were calculated using partial correlation analysis.

${ }^{\dagger}$ Adjusted for age.

$¥$ Adjusted for age and insulin resistance (HOMA-IR $\geq 1.32$ ).

${ }^{* *} \mathrm{P}<0.001$.

(4) High blood pressure: a systolic blood pressure of $\geq 130 \mathrm{mmHg}$ or a diastolic blood pressure of $\geq 85 \mathrm{mmHg}$.

(5) Hyperglycemia: a fasting plasma glucose concentrations of $\geq 110 \mathrm{mg} / \mathrm{dl}$.

All analyses were conducted using the SAS version 9.1 software package (SAS Institute Inc, Cary, NC, USA). All statistical tests were 2-sided, and statistical significance was accepted for P-values of $<0.05$.

\section{Results}

General characteristics of the 29,319 participants $(18,290$ for men and 11,029 for women) are presented in Table 1.
Mean subject age was 43.3 years and mean ALT levels were 28.4 IU/L for men and 16.7 IU/L for women. Prevalence of metabolic syndrome was $31.9 \%$ among men and $14.7 \%$ among women. Table 2 shows clinical measurements stratified by ALT quartile. Subjects in the highest quartile were older, and more likely to be obese, have higher fasting glucose and TG concentrations, lower HDL cholesterol concentrations, and higher blood pressures than those in the lowest quartile. ALT was found to be significantly correlated with the following metabolic syndrome components, ie, blood pressure, waist circumference, TG, HDL cholesterol, and fasting glucose in men and women after adjusting for age, alcohol, smoking, and insulin resistance (Table 3 ). In addition, after adjusting for insulin resistance, ALT was found to be correlated with all components in both men and women. Furthermore, an elevated ALT was found to be associated with an increased risk of metabolic syndrome after adjusting for age, alcohol intake, and smoking status (Table 4). Adjusting for insulin resistance attenuated the association between ALT and metabolic syndrome, but it remained strongly significant. Subjects in the highest ALT quartiles were found to have a higher risk of metabolic syndrome than subjects in lowest quartiles $(\mathrm{OR}=$ $4.56,95 \%$ confidence interval $(\mathrm{CI})=4.07-5.11$ for men and $\mathrm{OR}=3.80,95 \% \mathrm{CI}=2.96-4.90$ for women $)$.

Figure 1 demonstrates the effect of insulin resistance on the association between ALT levels and metabolic syndrome. There is no interaction, but those with insulin resistance showed a stronger relation between serum ALT and metabolic syndrome than those without insulin resistance. The association between serum ALT and metabolic syndrome in those $<50$ was greater than that in those $\geq 50$ (Figure 2). In those $<50$, serum ALT was found to be associated with the risk of

\begin{tabular}{|c|c|c|c|c|c|c|}
\hline \multirow{2}{*}{ ALT Quartiles* } & \multicolumn{3}{|c|}{ Men $(n=18,290)$} & \multicolumn{3}{|c|}{ Women $(n=11,029)$} \\
\hline & Case & Model $1^{\dagger}$ & Mode $2^{\ddagger}$ & Case & Model $1^{\dagger}$ & Model $2^{\ddagger}$ \\
\hline Quartile 1 & 589 & 1.00 & 1.00 & 83 & 1.00 & 1.00 \\
\hline Quartile 2 & 1,125 & $1.74(1.55-1.95)$ & $1.60(1.43-1.80)$ & 283 & $1.54(1.19-1.99)$ & $1.50(1.15-1.96)$ \\
\hline Quartile 3 & 1,710 & $2.96(2.66-3.30)$ & $2.41(2.15-2.69)$ & 376 & $2.35(1.82-3.04)$ & $2.17(1.67-2.83)$ \\
\hline Quartile 4 & 2,404 & $6.99(6.28-7.80)$ & $4.56(4.07-5.11)$ & 874 & $4.91(3.85-6.27)$ & $3.80(2.96-4.90)$ \\
\hline
\end{tabular}

Abbreviation see in Table 1.

${ }^{*}$ Gender-specific quartile mean of ALT: men (<17.0, 17.0-22.9, 23.0-32.9, $\left.\geq 33.0 \mathrm{IU} / \mathrm{L}\right)$, women $(<11.0,11.0-14.9,15.0-18.9, \geq 19.0 \mathrm{IU} / \mathrm{L})$.

${ }^{\dagger}$ Adjusted for age, alcohol intake and smoking status.

$\ddagger$ Adjusted for Model 1 and insulin resistance (HOMA-IR $\geq 1.32$ ).

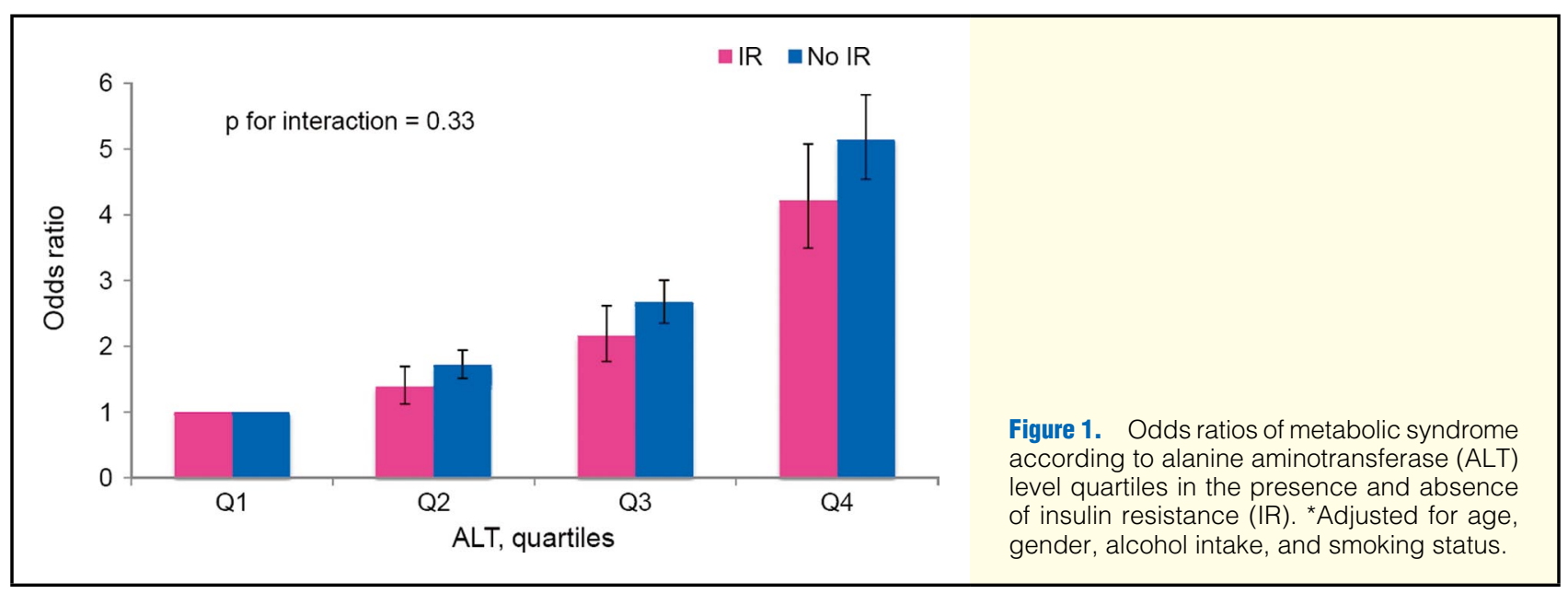



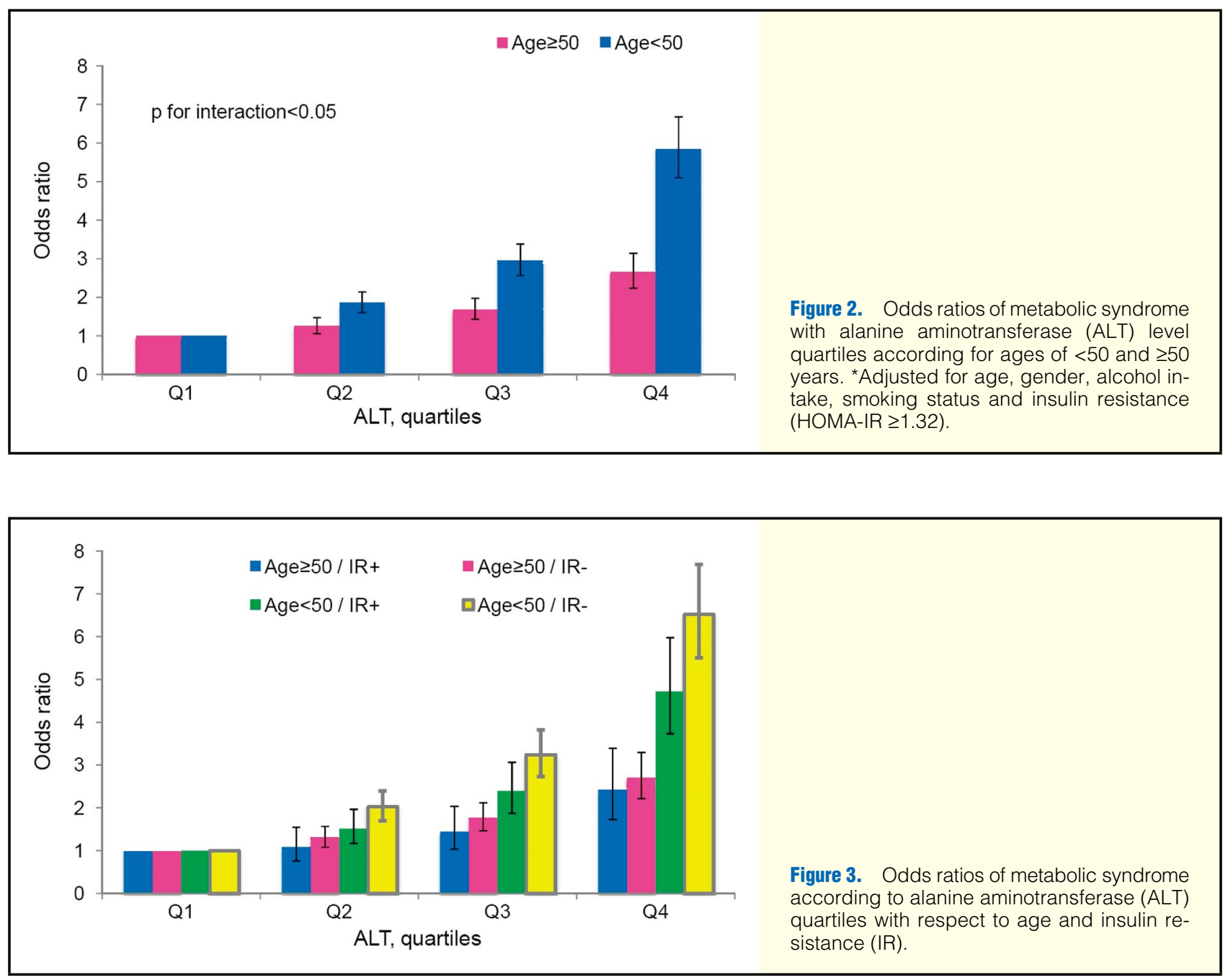

metabolic syndrome after adjusting for gender, alcohol intake, smoking status, and insulin resistance $(\mathrm{OR}=5.84,95 \% \mathrm{CI}=$ 5.10-6.68). Figure 3 shows the risk of metabolic syndrome for ALT quartiles stratified by age and insulin resistance. For all participants, those in the first quartile aged $\geq 50$ with insulin resistance were found to have the lowest association between ALT and metabolic syndrome. Participants in the fourth quartile with an age of $<50$ without insulin resistance, had a risk of metabolic syndrome that was 6.51-fold higher that that of comparable subjects in the $1^{\text {st }}$ quartile. Therefore, the association between ALT and metabolic syndrome was stronger in relatively healthy subjects.

\section{Discussion}

The present study confirms that serum ALT level is strongly correlated with the risk of metabolic syndrome, after controlling for several potential confounders. Moreover, although this association was attenuated by adjusting for insulin resistance, it remained strongly significant. Furthermore, this study shows that the risk of metabolic syndrome increases with ALT level more so in those without insulin resistance. The present study also shows that these associations are modified by age, and in particular, the association is stronger in the younger age group.

The findings of the present study are in concordance with several previous studies. In the Insulin Resistance Atherosclerosis Study, Hanley et al found that ALT predicts metabolic syndrome in 632 subjects aged between 40 and 69 years. ${ }^{18}$ Moreover, in a study of male Japanese office workers, Nakanishi et al found that ALT is associated with 7-year risk of metabolic syndrome after multivariate adjustment. ${ }^{22}$ In the Hoorn Study, Schindhelm et al found an association between ALT and the 6-year risk of the metabolic syndrome in Caucasians. Thus, the above studies provide further evidence that ALT is a predictor of further metabolic derangement. However, most of these previous studies conducted in Asians or Caucasians have specifically addressed the association between ALT and metabolic syndrome, whereas few studies have examined the effect of insulin resistance on the association between ALT and metabolic syndrome. ${ }^{19}$ The Hoorn Study also pointed out that ALT is related to metabolic syndrome independent of insulin resistance, ${ }^{19}$ however, Hoorn Study consisted of only elderly Caucasian men and women. Although this study is a cross-sectional study, this study is valued due to the fact that results were confirmed in Korea.

Metabolic syndrome is known to be closely related to insulin resistance, but the extent to which the metabolic syndrome and insulin resistance overlap has not been well delineated. It is controversial whether insulin resistance should be added to the list of metabolic syndrome components. ${ }^{23-25}$ Several studies have concluded both insulin resistance and metabolic 
syndrome simultaneously predict the presence of cardiovascular disease. ${ }^{26-29}$ According to the findings of the Insulin Resistance Atherosclerosis Study, ALT is associated with insulin resistance independently of conventional and more detailed metabolic measures. ${ }^{14}$ Furthermore, insulin resistance has been shown to be associated with fatty liver and ALT to be most closely related with liver fat accumulation. ${ }^{16}$ However, although recent studies have reported that elevated ALT is associated with insulin resistance, ${ }^{19}$ it has not been adequately shown that ALT levels directly increase the risk of metabolic syndrome.

If insulin resistance acts as a mediator of the association between ALT and metabolic syndrome, there should be no association between ALT and metabolic syndrome after controlling for HOMA-IR. However, in the present study, this association between ALT and metabolic syndrome was maintained after controlling for HOMA-IR and was found to be higher in those with no insulin resistance than those with insulin resistance. Nevertheless, it should be noted that in the present study, insulin resistance was measured using HOMA index and the gold standard euglycemic-hyperinsulinemic clamp test is used for determining insulin resistance in the clinical laboratories. ${ }^{30}$ However, although this test measures insulin resistance both directly and accurately, HOMA-IR is also known to be closely related to the glucose clamp techniques $(\mathrm{r}=-0.820, \mathrm{P}<0.0001) .{ }^{31} \mathrm{In}$ addition, HOMA-IR is not a perfect indicator to conclude that ALT was related to metabolic syndrome independent of insulin resistance. Some of the subjects with high ALT might have a combination of insulin resistance and insufficient secretion of insulin and that is why HOMA-IR showed a normal range in these subjects. So, we did the analyses for insulin secretion (HOMA- $\beta)^{32}$ that ALT of both insulin secretion adjusted model (HOMA- $\beta$ ) and insulin resistance and insulin secretion adjusted model are associated with MS independently (data not shown). Thus, further study is required to elucidate the association between ALT and metabolic syndrome independently of insulin resistance.

Although several studies have reported that the prevalence of the metabolic syndrome increased strongly with age, ${ }^{33-38}$ no attempt has been made to determine the association between ALT and metabolic syndrome with respect to age. Our study shows that increased ALT levels were associated with the risk of the metabolic syndrome in those $<50$ years old. Furthermore, the highest association found between ALT and metabolic syndrome was for those aged lesser than 50 years with no insulin resistance. Therefore, this study highlights the importance of individuals relatively low risk group, to screen themselves regularly for metabolic syndrome, having displayed a strong association with that age group relatively lower risk group.

Several limitations of the present study require consideration. First, due to the cross-sectional design, this study could not elucidate mechanisms or determine the direction of causality. Second, we did not consider for factors that might have induced ALT increases, such as a hepatotoxic drugs history. It also should be borne in mind that the present study was conducted on apparently healthy people who voluntarily underwent a health checkup at hospitals, which presents difficulties concerning the generalization of our results to other populations. Third, we cannot directly measure fatty liver. The increase of ALT is thought to indicate the grade of fatty liver which is one of the types of visceral fat. ${ }^{39}$ It is also known that hepatic steatosis is closely related to insulin resistance. ${ }^{40}$ Although, we cannot directly measure fatty liver, we re-did the analysis for relatively healthy population (BMI $<25$ and TG <150) with low degree of fatty liver. ALT was significantly associated with metabolic syndrome independent of insulin resistance in healthy group.

In conclusion, in the present study, it was found that elevated ALT levels are associated with the risk of metabolic syndrome in a Korean population. Our findings also indicate that further studies are warranted on the pathogenesis of metabolic syndrome and on the causal relationship between ALT levels and metabolic syndrome. In addition, a further cohort study is needed to determine whether ALT levels can be used for prediction of the risk of metabolic syndrome.

\section{Acknowledgments}

This study was supported by the Seoul City R\&BD program (grant no. 10526).

\section{References}

1. Sattar N, Gaw A, Scherbakova O, Ford I, O'Reilly DS, Haffner $\mathrm{SM}$, et al. Metabolic syndrome with and without $\mathrm{C}$-reactive protein as a predictor of coronary heart disease and diabetes in the West of Scotland Coronary Prevention Study. Circulation 2003; 108: $414-$ 419.

2. Alexander CM, Landsman PB, Teutsch SM, Haffner SM. NCEPdefined metabolic syndrome, diabetes, and prevalence of coronary heart disease among NHANES III participants age 50 years and older. Diabetes 2003; 52: 1210-1214.

3. Tong PC, Kong AP, So WY, Yang X, Ho CS, Ma RC, et al. The usefulness of the International Diabetes Federation and the National Cholesterol Education Program's Adult Treatment Panel III definitions of the metabolic syndrome in predicting coronary heart disease in subjects with type 2 diabetes. Diabetes Care 2007; 30: $1206-$ 1211.

4. Chien KL, Hsu HC, Sung FC, Su TC, Chen MF, Lee YT. Metabolic syndrome as a risk factor for coronary heart disease and stroke: An 11-year prospective cohort in Taiwan community. Atherosclerosis 2007; 194: 214-221.

5. Higashiyama A, Okamura T, Ono Y, Watanabe M, Kokubo Y, Okayama A. Risk of smoking and metabolic syndrome for incidence of cardiovascular disease: Comparison of relative contribution in urban Japanese population: The Suita study. Circ J 2009; 73: 2258 2263.

6. Malik S, Wong ND, Franklin SS, Kamath TV, L'Italien GJ, Pio JR, et al. Impact of the metabolic syndrome on mortality from coronary heart disease, cardiovascular disease, and all causes in United States adults. Circulation 2004; 110: 1245-1250.

7. Hunt KJ, Williams K, Hazuda HP, Stern MP, Haffner SM. The metabolic syndrome and the impact of diabetes on coronary heart disease mortality in women and men: The San Antonio Heart Study. Ann Epidemiol 2007; 17: 870-877.

8. Protopsaltis I, Nikolopoulos G, Dimou E, Brestas P, Kokkoris S, Korantzopoulos $\mathrm{P}$, et al. Metabolic syndrome and its components as predictors of all-cause mortality and coronary heart disease in type 2 diabetic patients. Atherosclerosis 2007; 195: 189-194.

9. Saito I, Iso H, Kokubo Y, Inoue M, Tsugane S. Metabolic syndrome and all-cause and cardiovascular disease mortality: Japan Public Health Center-based Prospective (JPHC) Study. Circ J 2009; 73: 878-884.

10. Prati D, Taioli E, Zanella A, Della Torre E, Butelli S, Del Vecchio $\mathrm{E}$, et al. Updated definitions of healthy ranges for serum alanine aminotransferase levels. Ann Intern Med 2002; 137: 1-10.

11. Piton A, Poynard T, Imbert-Bismut F, Khalil L, Delattre J, Pelissier E, et al. Factors associated with serum alanine transaminase activity in healthy subjects: Consequences for the definition of normal values, for selection of blood donors, and for patients with chronic hepatitis C. MULTIVIRC Group. Hepatology 1998; 27: 1213-1219.

12. Kahn RA, Johnson G, Aach RD, Hines A, Ellis FR, Miller WV. The distribution of serum alanine aminotransferase levels in a blood donor population. Am J Epidemiol 1982; 115: 929-940.

13. Oh SY, Cho YK, Kang MS, Yoo TW, Park JH, Kim HJ, et al. The association between increased alanine aminotransferase activity and metabolic factors in nonalcoholic fatty liver disease. Metabolism 2006; 55: 1604-1609.

14. Hanley AJ, Wagenknecht LE, Festa A, D'Agostino RB Jr, Haffner SM. Alanine aminotransferase and directly measured insulin sensi- 
tivity in a multiethnic cohort: The Insulin Resistance Atherosclerosis Study. Diabetes Care 2007; 30: 1819-1827.

15. Bo S, Gambino R, Durazzo M, Guidi S, Tiozzo E, Ghione F, et al. Associations between gamma-glutamyl transferase, metabolic abnormalities and inflammation in healthy subjects from a populationbased cohort: A possible implication for oxidative stress. World $J$ Gastroenterol 2005; 11: 7109-7117.

16. Westerbacka J, Cornér A, Tiikkainen M, Tamminen M, Vehkavaara $\mathrm{S}$, Häkkinen AM, et al. Women and men have similar amounts of liver and intra-abdominal fat, despite more subcutaneous fat in women: Implications for sex differences in markers of cardiovascular risk. Diabetologia 2004; 47: 1360-1369.

17. Jeong SK, Nam HS, Rhee JA, Shin JH, Kim JM, Cho KH. Metabolic syndrome and ALT: A community study in adult Koreans. Int J Obes Relat Metab Disord 2004; 28: 1033 - 1038

18. Hanley AJ, Williams K, Festa A, Wagenknecht LE, D'Agostino RB Jr, Haffner SM. Liver markers and development of the metabolic syndrome: The insulin resistance atherosclerosis study. Diabetes 2005; 54: 3140-3147.

19. Schindhelm RK, Dekker JM, Nijpels G, Stehouwer CD, Bouter LM, Heine RJ, et al. Alanine aminotransferase and the 6-year risk of the metabolic syndrome in Caucasian men and women: The Hoorn Study. Diabet Med 2007; 24: 430-435.

20. Executive summary of the Third Report of the National Cholesterol Education Program (NCEP) Expert Panel on Detection, Evaluation, and Treatment of High Blood Cholesterol in Adults (Adult Treatment Panel III). JAMA 2001; 285: 2486-2497.

21. Steering Committee of the Western Pacific Region of the World Health Organization, the International Association for the Study of Obesity, and the International Obesity Task Force. The Asia-Pacific Perspective: Redefining Obesity and its Treatment. Melbourne: Health Communications Australia Pty Ltd, 2000.

22. Nakanishi N, Suzuki K, Tatara K. Serum gamma-glutamyltransferase and risk of metabolic syndrome and type 2 diabetes in middleaged Japanese men. Diabetes Care 2004; 27: 1427-1432.

23. Grundy SM, Brewer HB Jr, Cleeman JI, Smith SC Jr, Lenfant C. Definition of metabolic syndrome: Report of the National Heart, Lung, and Blood Institute/American Heart Association conference on scientific issues related to definition. Circulation 2004; 109: $433-438$.

24. Onat A, Hergenç G, Türkmen S, Yazici M, Sari I, Can G. Discordance between insulin resistance and metabolic syndrome: Features and associated cardiovascular risk in adults with normal glucose regulation. Metabolism 2006; 55: 445-452.

25. Lann D, LeRoith D. Insulin resistance as the underlying cause for the metabolic syndrome. Med Clin North Am 2007; 91: 1063 1077.

26. Tzou WS, Douglas PS, Srinivasan SR, Bond MG, Tang R, Chen W, et al. Increased subclinical atherosclerosis in young adults with metabolic syndrome: The Bogalusa Heart Study. J Am Coll Cardiol 2005; 46: 457-463.
27. McNeil AM, Rosamond WD, Girman CJ, Heiss G, Golden SH, Duncan BB, et al. Prevalence of coronary heart disease and carotid arterial thickening in patients with the metabolic syndrome (the ARIC study). Am J Cardiol 2004; 94: 1249-1254.

28. Ellison RC, Shang Y, Wagenknecht LE, Eckfeldt JH, Hopkins PN, Pankow JS, et al. Relation of the metabolic syndrome to calcified atherosclerotic plaque in the coronary arteries and aorta. Am J Cardiol 2005; 95: 1180-1186.

29. Bertoni AG, Wong ND, Shea S, Ma S, Liu K, Preethi S, et al. Insulin resistance, metabolic syndrome, and subclinical atherosclerosis: The Multi-Ethnic Study of Atherosclerosis (MESA). Diabetes Care 2007; 30: 2951-2956.

30. DeFronzo RA, Tobin JD, Andres R. Glucose clamp technique: A method for quantifying insulin secretion and resistance. Am J Physiol 1979; 237: E214-E223.

31. Bonora E, Targher G, Alberiche M, Bonadonna RC, Saggiani F, Zenere MB, et al. Homeostasis model assessment closely mirrors the glucose clamp technique in the assessment of insulin sensitivity. Diabetes Care 2000; 23: 57-63.

32. González-Ortiz M, Martínez-Abundis E. Comparison of several formulas to assess insulin action in the fasting state with the hyperglycemic-hyperinsulinemic clamp technique in healthy individuals. Rev Invest Clin 2003; 55: 419-422.

33. Kuzuya M, Ando F, Iguchi A, Shimokata H. Age-specific change of prevalence of metabolic syndrome: Longitudinal observation of large Japanese cohort. Atherosclerosis 2007; 191: 305-312.

34. Ford ES, Giles WH, Dietz WH. Prevalence of the metabolic syndrome among US adults: Findings from the third National Health and Nutrition Examination Survey. JAMA 2002; 287: 356-359.

35. Gu D, Reynolds K, Wu X, Chen J, Duan X, Reynolds RF, et al. Prevalence of the metabolic syndrome and overweight among adults in China. Lancet 2005; 365: $1398-1405$.

36. Azizi F, Salehi P, Etemadi A, Zahedi-Asl S. Prevalence of metabolic syndrome in an urban population: Tehran Lipid and Glucose Study. Diab Res Clin Pract 2003; 61: 29-37.

37. Park HS, Lee SY, Kim SM, Han JH, Kim DJ. Prevalence of the metabolic syndrome among Korean adults according to the criteria of the International Diabetes Federation. Diabetes Care 2006; 29: 933-934.

38. Park HS, Kim SM, Lee JS, Lee J, Han JH, Yoon DK, et al. Prevalence and cardiovascular disease risk of the metabolic syndrome using National Cholesterol Education Program and International Diabetes Federation definitions in the Korean population. Metabolism 2007; 56: 552-558.

39. Cnop M, Landchild MJ, Vidal J, Havel PJ, Knowles NG, Carr DR, et al. The concurrent accumulation of intra-abdominal and subcutaneous fat explains the association between insulin resistance and plasma leptin concentrations: Distinct metabolic effects of two fat compartments. Diabetes 2002; 51: 1005-1015.

40. Shimabukuro M. Cardiac adiposity and global cardiometabolic risk: New concept and clinical implication. Circ J 2009; 73: 27-34. 